\title{
The 5 R's: An Emerging Bold Standard for Conducting Relevant Research in a Changing World
}

C. J. Peek, $P b D^{1}$

Russell E. Glasgow, $P b D^{2}$

Kurt C. Stange, $M D, P b D^{3}$

Lisa M. Klesges, $P b D^{4}$

E. Peyton Purcell, MPH

Rodger S. Kessler, PbD, ABPP

${ }^{1}$ Department of Family Medicine and Community Health, University of Minnesota Medical School, Minneapolis, Minnesota

${ }^{2}$ Department of Family Medicine and Colorado Health Outcomes Program, University of Colorado, Denver, Colorado

${ }^{3}$ Department of Family Medicine \& Community Health, Department of Epidemiology \& Biostatistics, and Department of Sociology, Case Comprehensive Cancer Center, Cleveland Clinical \& Translational Science Collaborative, Case Western Reserve University, Cleveland, Ohio

${ }^{4}$ School of Public Health, University of Memphis, Memphis, Tennessee

${ }^{5}$ Clinical Research Directorate/CMRP SAIC-Frederick, Inc, Frederick National Laboratory for Cancer Research, Frederick, Maryland

${ }^{6}$ Department of Family Medicine and the Center for Clinical and Translational Science, University of Vermont College of Medicine, Burlington, Vermont

Conflicts of interest: authors report none.

\section{CORRESPONDING AUTHOR}

C. J. Peek, PhD

Department of Family Medicine and Community Health

University of Minnesota Medical School

MMC 381, 420 Delaware St SE

Minneapolis, MN 55455-0392

cjpeek@umn.edu

\begin{abstract}
Research often fails to find its way into practice or policy in a timely way, if at all. Given the current pressure and pace of health care change, many authors have recommended different approaches to make health care research more relevant and rapid. An emerging standard for research, the " $5 \mathrm{R}$ 's" is a synthesis of recommendations for care delivery research that (1) is relevant to stakeholders; (2) is rapid and recursive in application; (3) redefines rigor; (4) reports on resources required; and (5) is replicable. Relevance flows from substantive ongoing participation by stakeholders. Rapidity and recursiveness occur through accelerated design and peer reviews followed by short learning/implementation cycles through which questions and answers evolve over time. Rigor is the disciplined conduct of shared learning within the specific changing situations in diverse settings. Resource reporting includes costs of interventions. Replicability involves designing for the factors that may affect subsequent implementation of an intervention or program in different contexts. These R's of the research process are mutually reinforcing and can be supported by training that fosters collaborative and reciprocal relationships among researchers, implementers, and other stakeholders. In sum, a standard is emerging for research that is both rigorous and relevant. Consistent and bold application will increase the value, timeliness, and applicability of the research enterprise.
\end{abstract}

Ann Fam Med 2014;12:447-455. doi: 10.1370/afm.1688.

\section{THE NEED FOR RELEVANT RESEARCH IN A RAPIDLY CHANGING HEALTH CARE WORLD}

$\Lambda$ ccelerated pressure for change in health care creates an exploding need for relevant and rapidly generated new information. A growing volume of care delivery experiments around the country pose questions that research can help answer: Which interventions or system changes improve care, access, safety, or quality-and for which populations, under what conditions? Which system changes reduce underuse, overuse, or misuse? Which approaches are implementable and engaging to clinicians and patients - and can be done at reasonable cost? $?^{1,2}$

Evolving clinical, organizational, and business models for health care, such as patient-centered medical homes ${ }^{3}$ and accountable care organizations ${ }^{4}$ need rapidly generated research evidence in real-world experiments for multiple stakeholders: implementers who want to improve their practices; purchasers who want to pay for value ${ }_{i}$ health plans that administer benefits and take risks for care provided, policy makers who are being asked to change "the rules of the game" to support new approaches; patients who wish to know their care is effective, safe, and worth their effort and money; and public health, community groups, and agencies who wish to see improved health at a societal level., ${ }^{5,6}$

The current research approach is not up to this challenge. Most recent research is slow to influence practice, does so only in pockets, or does not address practical needs for decision making. ${ }^{7-9}$ Innovative ideas to remedy this situation have been proposed and some implemented. Yet the overall problem remains. It is time to pull together and implement changes 
in research paradigms and habits to better meet the research needs of changing health care delivery. ${ }^{10-14}$

The threads of a fresh research paradigm are already apparent, having been suggested separately in many publications, ${ }^{15-17}$ but need to be woven together to form a picture- the whole cloth with which to tailor research to answer the important stakeholder questions. This article weaves those threads together in the form of an integrated set of " $5 \mathrm{R}$ 's" to guide research.

\section{THE 5 R'S OF HEALTH CARE DELIVERY RESEARCH}

Below we articulate the issues and how they can be addressed through the 5 R's to generate health care

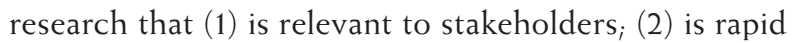
and recursive in application ${ }_{i}(3)$ redefines rigor $_{i}(4)$ reports on resources required $d_{i}$ and (5) is replicable. Relevance flows from substantive ongoing participation by stakeholders. Rapidity and recursiveness occur through accelerated design and grant reviews followed by short learning/implementation cycles through which questions and answers evolve over time. Rigor is the disciplined conduct of shared learning within the specific changing situations in diverse settings. Resource reporting includes costs of interventions and likely cost of replication in other settings. Replicability involves designing for the factors that may affect subsequent implementation of an intervention or program in different contexts.

\section{Relevant to Stakeholders}

\section{What Is the Issue?}

Perceived lack of relevance is cited as the primary reason practitioners do not use research. ${ }^{18-21}$ Research must generate setting-based evidence designed to flow into practice realities and meet stakeholder needs; as has been stated, "If we want more evidence-based practice, we need more practice-based evidence."22

\section{How Can It Be Addressed?}

Involve end users meaningfully and continuously from the outset in forming research questions and selecting outcomes. 2,5,15,16,18,21-24 Research agendas should have origins in need on the ground ${ }^{16}$ - with stakeholders being not only customers for research, but also producers of meaningful questions. Questions come from implementers, policy makers, health plans, purchasers, and patients-with researchers who listen and translate different user concerns into researchable questions. ${ }^{5,24}$ Such participatory, practice- or community-based "partnership research"15 extends to all phases of research: question generation, designs and measures, implementation, interpretation, presentation, and application of results.
Build an ultimate use perspective into all stages of the research process. If research waits too long before considering sustainable real-world implementation, investment in the preceding research may prematurely "freeze" the intervention in ways not compatible with later use. Engaging stakeholders in how to implement at earlier phases may help avoid retooling and reduce the time to real-world application.

Seek continuation, not only translation. Health care practitioners are arguably more likely to apply and sustain what is learned from research in their own practices. ${ }^{25}$ The question becomes not, "how do we translate this to our practice?" but, "how do we continue, adapt, and spread what we just learned in our practice?" If done widely, this continuation could make research relevant and make knowledge generation part of the fabric of practice.

\section{Rapid and Recursive in Application}

What Is the Issue?

It is not acceptable that it takes 17 years on average for a $14 \%$ uptake of funded research into practice. ${ }^{7}$ In a rapidly changing environment, we need to find ways to accelerate the research enterprise.

\section{How Can It Be Addressed?}

Engage stakeholders in rapid-learning research systems. In "rapid-learning health care," "routinely collected real-time clinical data drive the process of scientific discovery, which becomes a natural outgrowth of patient care." ${ }^{26}$ Components may include databases or registries organized by populations, electronic health records, guidelines and clinical decision support, patient engagement, and multiple sponsors or research networks. ${ }^{26,27}$ In "rapid-learning research systems ${ }^{121}$ researchers, funders, implementers, health systems, and community partners are brought together to develop questions, answer them, and then ask new questions of practical importance.

Streamline review processes. The health care delivery world moves on with new partners, questions, and technology, whereas traditional grant application and review often takes a long time. ${ }^{21}$ Rapid review processes $^{26}$ that shorten the time from conception of a study to its approval, funding, and start can help keep studies timely and relevant.

Pose research questions to multiple networked practices. Practice-based research networks (PBRNs) are practices that work together to answer health care questions and translate findings into practice. PBRNs can generate relevant questions from stakeholders, design research, and collect data that result in rapid answers from large data sets, including deidentified data from clinical and financial records stored in electronic health records from 
natural experiments happening in real time, such as data for complex patients treated under real-world conditions by real-world clinicians. Some of these practice settings, as well as public health system research networks ${ }_{1}^{28}$ are becoming true "learning organizations ${ }^{127}$ where quality improvement research is included with, not separated from, more experimental findings.

Allow discoveries within a study to influence the study.

Discoveries, sometimes unexpected, can modify subsequent data collection and measurement. Data collection is no longer only at fixed points, using static measures. Implementation or study processes are continuously improved along the way. This is a recursive and rapid learning situation. ${ }^{27}$ When discoveries in a study begin to appear, they may reshape stakeholder questions or begin to answer others. The next set of questions may begin to emerge, along with energy for answering those reshaped or more insightful questions As discoveries roll in, stakeholders, in partnership with researchers, guide these iterations.

\section{Redefines Rigor}

\section{What Is the Issue?}

Scientific rigor is essential, but common conceptions of rigor may limit the range of real-world situations that can be studied - and methods, settings, and populations with which to do so. The hallmark of rigor has been the "gold standard" efficacy randomized controlled trial (RCT) emphasizing internal validity.

\section{How Can It Be Addressed?}

We suggest a modified version of rigor suited to broader questions meaningful to multiple stakeholders and answered in heterogeneous populations and settings with attention to transportability and sustainable implementation.

Regard rigor as a property of a series of decisions, observations, and relationships rather than of techniques. ${ }^{29}$ Rigorous research (1) is systematic and organized about concepts, tools, data collection, measures, procedures, and analyses $;$ (2) checks for superfluous connections and confounding variables; (3) has controls and conclusions justified by standards of evidence; and (4) uses transparent descriptions of what was done. Rigor is not defined as a list of certain techniques and exclusion of others. Particular experimental designs, data collection, or analysis techniques are not always considered more rigorous than others or that any one is the optimal design for all questions and all situations. Others have commented, "If techniques are tools in a researcher's toolbox, then this is like saying that 'A saw is better than a hammer because it is sharper."' 29 Stated as a principle, "Research agenda determines the research methods rather than methods determine the research agenda."16
Give attention to both external and internal validity. Most methods developed to assess research quality focus predominantly or exclusively on internal validity. Rigor also implies attention to transparent reporting on issues related to generalizability. ${ }^{16,30}$

\section{Reporting on Resources}

What Is the Issue?

Use of health care resources is a major concern when a priority is to bend the cost curve. Stakeholders are making decisions among alternative care approaches based on the cost of interventions as well as on clinical effectiveness. Information on resources used to conduct or replicate interventions can be helpful in larger economic analysis, but is seldom well reported. ${ }^{31}$

\section{How Can It Be Addressed?}

Use a consistent vocabulary for reporting. For example, measuring cost includes money, but also clinician and staff time and energy, plus intervention systems, infrastructure, or training costs. There are start-up costs, ongoing costs, and opportunity costs. There are costs of doing a study intervention, and likely costs of recreating it in another setting. Costs incurred in one place or to one stakeholder may save costs in some other place or for another stakeholder.

Report on as many of the relevant costs of different interventions as possible and do so in a standard manner. ${ }^{14,32,33}$ For example, what did the program in question cost to promote and implement, and what are estimates of what it would cost to replicate a similar program under different conditions or settings? Such estimates do not require researchers to do complex economic or cost-benefit analyses, but reporting on resources is important to those who pay attention to value in health care. Although value may mean many things to many people, it is being defined and becoming part of efforts to be rigorous, transparent, and relevant to stakeholders, ${ }^{34}$ including patients who have their own perspective on value. ${ }^{35}$

\section{Replicability}

\section{What Is the Issue?}

Research design can help address questions regarding how an innovation will perform in a new system with different contextual influences. ${ }^{36}$ Replication of findings is increasingly recognized ${ }^{37}$ as a major challenge across the translation spectrum from basic discovery (eg, genomewide association studies) to community interventions. The conditions under which a finding can be replicated are central to understanding robust effects that can be reasonably expected under various conditions. Hence, researchers must design for replicability and report results needed for reproduc- 
ibility_either under the same or different conditions in which the findings are likely to be applied.

\section{How Can It Be Addressed?}

Design for sustainable implementation from the start. This approach is arguably more efficient and effective if it saves rework for real-world application. We recommend asking 3 questions: (1) is the study designed to inform implementation - and re-invention in different settings? (2) is the "how" reported as well as the "what" of interventions, and to what extent are procedures replicable in similar or diverse settings? and (3) are contextual factors reported that are important to understanding what happened and why-for example, relevant policies, and inclusion and exclusion criteria for settings and staff as well as patients?

These strategies can go a long way toward making findings replicable, realizing that not every study can be transported to other settings. But such data will allow others to make reasonable judgments about what aspects to retain and what to change for replication or reinvention in a different time and place, using relevant domains for contextual factors. ${ }^{38}$

\section{EXAMPLES}

Some of the 5 R's have found their way into research studies, networks, and tools. Table 1 describes a few examples. Readers can likely cite other examples or see other R's in these. The 5 R's are emerging not as a response to a completed record of implementation in full scope, but as a logical (and promising) challenge to package in application the separate elements already abundantly demonstrated in the literature, but not yet combined to full effect in more than a few examples. What is "bold" is the proposal to routinely apply the 5 R's as a package and to take on the substantial challenges of practical implementation and evolution. For inspiration, consider McDonnell Douglas' bold integration of 5 existing technologies for the first time in 1 airplane (the 1935 DC-3), the innovation that swept away the competition and opened the era of commercial air travel, when a plane with 4 of those technologies failed commercially the previous year. ${ }^{51}$

\section{CONCLUSIONS}

Health care transformation needs the full benefit of research to inform decision making and discover new options. The research community owes it to its "customers" and the public to evolve its standards and methods for health care research. The 5 R's are offered as a next step in the developmental trajectory of an evolving field-a framework for a much needed discus- sion and adjustment of criteria for what is considered high-quality research.

\section{Routinely Apply the Complete Package of 5 R's}

As is the case for other models-for example, the Reach Effectiveness-Adoption Implementation Maintenance (RE-AIM) evaluation model, ${ }_{1}^{52,53}$ the Chronic Care Model ${ }^{54}$ and the Institute of Medicine 6 quality aims $^{55}$-the effect of the 5 R's model comes not from doing separate R's or even 2 or 3 of them, but from doing them all in an integrated fashion whereby each reinforces the others. The 5 R's are proposed to work together across stages of the research and dissemination process. Table 2 shows a research "preflight" checklist.

\section{Overcome the Practical Challenges of Implementing the R's}

There is little doubt that implementing the 5 R's on a meaningful scale will require continued changes in thinking and infrastructure pointed out in literature on the separate R's. Table 3 summarizes such changes.

Although many of these changes are under way in different places in different ways, considerable challenges remain. We believe that emerging stakeholder interests align well with the 5 R's and will drive such change. For example, the 2014 Academy Health report on improving the evidence base for Medicare policy making ${ }^{56}$ interviewed leaders in health policy and care delivery for their most pressing health services research needs over the next 3 to 5 years; it was research that (1) aims at understanding the performance of new organizational forms such as accountable care organizations and Medicare Advantage plans; (2) uses comparable data sets for performance of physician practices and new organizational arrangements; (3) engages with the promises and pitfalls of electronic data, rapid cycle research, and comparative effectiveness research ${ }_{i}(4)$ understands how the politics of evidence and policy affect research relevance and usefulness; and (5) builds relationships between researchers and policy makers, with study findings available at the time decisions were made-even if "best available" rather than "best" evidence. Although this study was focused on Medicare, we believe its lessons can be much more broadly taken.

In addition, we solicited feedback from a convenience sample of 8 stakeholders on the importance of research for practical decision making and on the 5 R's. Participants were balanced across practitioners, other implementers, and administrators. Responses indicated that relevant was the most important $\mathrm{R}$, with rapid a close second, followed by other R's - none of which were considered unimportant. The most important role for research in practical decisions was testing viabil- 


\section{Table 1. Examples of Projects Illustrating the R's}

\section{Example: Study/Project $/$ \\ Resource Title and Relevant R's}

\section{Study/Project/Resource Details}

\section{Particular studies and programs}

DIAMOND (Depression Improvement Across Minnesota-Offering a New Direction)

1. Relevant to stakeholders

2. Redefines rigor

3. Replicability

P4H (Prescription for Health)

1. Relevant to stakeholders

2. Recursive

3. Redefines rigor

4. Reports on resources

¡Viva Bien!

1. Relevant to stakeholders

2. Reports on resources

3. Replicability

MOHR (My Own Health Report)

1. Relevant to stakeholders

2. Rapid and recursive

3. Redefines rigor

4. Reports on resources

5. Replicability

\section{Research networks across studies}

PRC (Prevention Research Centers) of the Centers for Disease Control and Prevention

1. Relevant to stakeholders

2. Recursive

3. Replicability

QUERI (Quality Enhancement Research Initiative)

1. Relevant to stakeholders

2 . Rapid and recursive

3. Redefines rigor

4. Replicability

\section{Research application tools and resources}

RTIPs (Research Tested Intervention Programs)

1. Relevant to stakeholders

2. Reports on resources

3. Replicability

PRECIS (Pragmatic Explanatory Continuum Indicator Summary)

1. Relevant to stakeholders

2. Redefines rigor

3. Replicability an evolving research agenda. ${ }^{44}$ critical for replication.
The DIAMOND initiative for depression in primary care was a statewide collaborative of practices and health plans accompanied by a separately funded NIMH research study using a stepped wedge/phased intervention design. ${ }^{15,25,39,40}$ Practices launched the DIAMOND care process in cohorts, 6 months apart, with baseline data collected for all. Outcomes that mattered to different stakeholders were compared before and after launch across the many practices launching at different times. Outcomes were tracked using both quantitative and qualitative measures, including clinical outcomes, health plan claims data, patient surveys, and practice leader surveys regarding implementation.

An explicit balance of fidelity and adaptation to local situations-specifics that practices had to tailor for themselves (eg, choice of discipline for care managers, specific workflow for PHQ-9, type of data tracking system)-helped practices implement the DIAMOND intervention. ${ }^{41,42}$

P4H was an initiative of The Robert Wood Johnson Foundation (RWJF) with the Agency for Healthcare Research and Quality (AHRQ) to fund a collaboration of 17 PBRNs that developed and evaluated strategies to improve health behavior changes for multiple behaviors through linkage to community resources. ${ }^{43}$ Practices worked with researchers, and teams of researchers, and PBRN leaders worked with each other and with a cross-cutting research group to share evolving learning, and develop common measures and

Using mixed quantitative and qualitative methods (including researcher diary data and interviews) ${ }^{45}$ and cost analyses, $\mathrm{P} 4 \mathrm{H}$ showed that primary care practices have the ability to develop their linkages to connect patients with community resources ${ }^{46}$ to improve practice processes, ${ }^{47}$ health behavior counseling, and patient behavior change..$^{48}$

¡Viva Bien! ${ }^{32,33}$ was a randomized trial that provided a clear description of methods, implementation costs for a diabetes self-management program, and estimates of costs to replicate the program under different conditions, calculating incremental costs per behavioral, biologic, and quality-of-life change. It discussed how to separate the costs of development and research from implementation, and how to conduct relatively straightforward sensitivity analyses to estimate costs of replicating a program or policy under different conditions.

$\mathrm{MOHR}^{23,49}$ is a pragmatic participatory trial in which diverse primary care practices implement the collection of patient-reported information and provide patients advice, goal setting, and counseling in responsewith deliberate diversity of settings and populations to ensure greater generalizability of results. Practices, patients, funding agencies, and content experts were engaged throughout the study to take into account local resources and characteristics in design, implementation, evaluation, and dissemination.

Core elements of the study protocol were identified, with local tailoring to ensure implementation was relevant to local culture and practice on issues such as workflows, eligible patients, when and where assessment would be completed, whether electronic or paper, and how clinicians would receive the feedback. The trial used mixed methods, including cost analyses.

PRC directs a national network of 37 academic research centers at public health or medical schools with a preventive medicine residency program, translating research results into policy and public health practice. Centers have capacity for community-based, participatory prevention research needed to drive community changes to prevent and control chronic disease.

Research involves collaboration among partners bringing different expertise to the table, identifies research needs of partners, conducts research that builds on previous evidence for promising interventions, and recommends how interventions can be packaged for replication and adoption (http://www.cdc.gov/prc/index.htm).

QUERI is a Veterans Affairs initiative that brings together operations with research staff to address key gaps in quality and outcomes. It has contributed to remarkable and rapid improvements in the quality of care received by veterans across 10 conditions deemed high-risk or highly prevalent.

This initiative uses a 6 -step process to spot gaps in performance and to identify and implement interventions. QUERI studies and facilitates adoption of new treatments, tests, and models of care into routine clinical practice-feasibility, implementation, adoption, and impact (http://www.queri.research.va.gov/default.cfm).

RTIPs is a resource of the National Cancer Institute that provides information on the specific conditions under which each of their tested interventions has been evaluated and tools for addressing issues about applicability (http://rtips.cancer.gov/rtips).

New features related to external validity using the RE-AIM framework are included to help users better determine the likely public health impact of a given program if replicated in their setting. RTIPs also reports on the resources required to implement these programs.

PRECIS50 is a graphic representation of the extent to which a study is pragmatic (testing effect in usual conditions) vs explanatory (testing effect in ideal conditions) on 10 key dimensions.

If used consistently, this tool could greatly help practitioners decide whether a study is likely to be reproducible in their setting and researchers to investigate the dimensions along which similarity is more vs less

$\mathrm{NIMH}=$ National Institute of Mental Health; PBRN = practice-based research network; PHQ-9 = 9-item Patient Health Questionnaire; RE-AIM = Reach Effective-

ness-Adoption Implementation Maintenance. 
Table 2. Questions to Apply the 5 R's at Each Stage of the Research and Dissemination Process

\begin{tabular}{|c|c|c|c|c|c|}
\hline \multirow{2}{*}{$\begin{array}{l}\text { Stage of } \\
\text { Research }\end{array}$} & \multicolumn{5}{|c|}{ Bold Standard 5 R's } \\
\hline & Relevant to Stakeholders & Rapid and Recursive & Redefines Rigor & Reports on Resources & Replicability \\
\hline Design & $\begin{array}{l}\text { End users of this research } \\
\text { identified? } \\
\text { Stakeholders who need to } \\
\text { be involved identified? } \\
\text { Plan in place to engage } \\
\text { their perspectives? } \\
\text { Plan in place to gather } \\
\text { stakeholder questions } \\
\text { and what is important } \\
\text { to them? }\end{array}$ & $\begin{array}{l}\text { Rapid cycle measure- } \\
\text { ment and assess- } \\
\text { ment built into the } \\
\text { design? How? } \\
\text { Approach in place to } \\
\text { allow early discov- } \\
\text { eries to shape the } \\
\text { study? }\end{array}$ & $\begin{array}{l}\text { How is study system- } \\
\text { atic and pragmatic } \\
\text { about concepts, } \\
\text { measures, data col- } \\
\text { lection procedures, } \\
\text { and analysis plan? } \\
\text { Multiple methods } \\
\text { used? How? } \\
\text { Internal and external } \\
\text { validity balanced? } \\
\text { How? }\end{array}$ & $\begin{array}{l}\text { Intervention costs } \\
\text { (monetary and } \\
\text { other) measured? } \\
\text { How? } \\
\text { A standard vocabulary } \\
\text { for reporting on } \\
\text { resources in place? } \\
\text { What? }\end{array}$ & $\begin{array}{l}\text { Study designed to } \\
\text { inform imple- } \\
\text { mentation and } \\
\text { reinvention in } \\
\text { different set- } \\
\text { tings? How? } \\
\text { Likely relevant } \\
\text { settings for } \\
\text { this research } \\
\text { identified? }\end{array}$ \\
\hline Implementation & $\begin{array}{l}\text { Stakeholders involved in } \\
\text { ongoing refinement? } \\
\text { How? } \\
\text { Changes they sug- } \\
\text { gested along the way } \\
\text { recorded? } \\
\text { Changes suggested imple- } \\
\text { mented? Which ones? }\end{array}$ & $\begin{array}{l}\text { Short-cycle learning } \\
\text { taking place to } \\
\text { refine design and } \\
\text { measurement? } \\
\text { Is learning influenc- } \\
\text { ing the study? } \\
\text { How? }\end{array}$ & $\begin{array}{l}\text { Systematic approach } \\
\text { being followed to } \\
\text { concepts, tools, } \\
\text { data collection, } \\
\text { measures, proce- } \\
\text { dures, analyses? } \\
\text { Checks for bias and } \\
\text { superfluous con- } \\
\text { nections in place? } \\
\text { Clear description of } \\
\text { what is being done } \\
\text { recorded? }\end{array}$ & $\begin{array}{l}\text { Cost data gathered on } \\
\text { an ongoing basis? } \\
\text { Using a consistent } \\
\text { vocabulary for dif- } \\
\text { ferent kinds of costs? }\end{array}$ & $\begin{array}{l}\text { Contextual factors } \\
\text { documented } \\
\text { that are impor- } \\
\text { tant to under- } \\
\text { standing what } \\
\text { happened (and } \\
\text { why) in the } \\
\text { study setting? }\end{array}$ \\
\hline Reporting & $\begin{array}{l}\text { Diverse stakeholders } \\
\text { involved in interpreting } \\
\text { and reporting findings? } \\
\text { Their different interpreta- } \\
\text { tions reported? }\end{array}$ & $\begin{array}{l}\text { Emergent findings } \\
\text { shared on an ongo- } \\
\text { ing basis through- } \\
\text { out the study? } \\
\text { Have adaptations } \\
\text { made been } \\
\text { reported? }\end{array}$ & $\begin{array}{l}\text { Study methods } \\
\text { reported trans- } \\
\text { parently and } \\
\text { thoroughly? } \\
\text { Reported how } \\
\text { study checked for } \\
\text { potential biases } \\
\text { and superfluous } \\
\text { connections? } \\
\text { Reported how con- } \\
\text { clusions are justi- } \\
\text { fied by standards } \\
\text { of evidence? }\end{array}$ & $\begin{array}{l}\text { Study reports useful } \\
\text { cost data using a } \\
\text { defined vocabulary } \\
\text { for different kinds of } \\
\text { costs? } \\
\text { Estimates made for } \\
\text { costs under different } \\
\text { conditions? }\end{array}$ & $\begin{array}{l}\text { Contextual fac- } \\
\text { tors relevant to } \\
\text { reinvention in } \\
\text { new settings } \\
\text { reported, includ- } \\
\text { ing variation } \\
\text { across set- } \\
\text { tings or within } \\
\text { settings? }\end{array}$ \\
\hline Dissemination & $\begin{array}{l}\text { Target audiences, stake- } \\
\text { holders, or likely users } \\
\text { involved in next steps? } \\
\text { Findings expressed in lan- } \\
\text { guage and context that } \\
\text { mean something to dif- } \\
\text { ferent stakeholders? }\end{array}$ & $\begin{array}{l}\text { Guidelines provided } \\
\text { for adaptation and } \\
\text { customization/ } \\
\text { tailoring for future } \\
\text { use? }\end{array}$ & $\begin{array}{l}\text { Description included } \\
\text { for how internal } \\
\text { and external valid- } \\
\text { ity findings sup- } \\
\text { port wider use? }\end{array}$ & $\begin{array}{l}\text { Intervention cost data } \\
\text { discussed as a factor } \\
\text { in dissemination? }\end{array}$ & $\begin{array}{l}\text { Data-supported } \\
\text { suggestions } \\
\text { included about } \\
\text { the contexts for } \\
\text { which program } \\
\text { or intervention } \\
\text { is relevant or } \\
\text { reproducible? }\end{array}$ \\
\hline
\end{tabular}

ity of approaches in their own settings and available resources. Suggested reasons why research is often not useful were lack of relevance, rapidity, or good relationships with researchers. The 2 facets identified as making research more helpful were "faster turnaround" and building better relationships between researchers and clinicians; as one clinician put it, "Relationship is so important, you should put a 6 th $\mathrm{R}$ in there!"

\section{Recognize the Wide Range of Application for the 5 R's}

Admittedly aspirational, we do not expect every study to comprehensively address all 5 R's. We do not expect, for example, all epidemiologic research or basic mechanism studies to address all of them. Studies having as their long-term goal achieving translation to real-world settings or making a population impact, however, would benefit from considering each R, reporting on those most relevant, and discussing implications for the others. Examining the implications of all 5 R's should be useful in the vast majority of research studies, from efficacy to effectiveness to implementation and dissemination, not just for a few community translational "T4" studies, which are investigations of practice intervention effects on population health. This strategy would help align the pipeline of potential interventions with real-world pragmatic requirements.

\section{Build Better Relationships Using the 5 R's}

Practitioners often experience research as interfering with practical procedures or believe that researchers just want study participants to address their own 


\section{Table 3. Challenges and Changes for Routine Implementation of 5 R's}

\section{Challenges}

Accelerating the pace and iterative nature of the research enterprise

Decision-maker needs outpace current speed of review cycles: grant review; funding decision; IRB approval and modification processes

Study implementation time frames

Publication cycles not amenable to "just in time" decisions; slow review and release of findings (see more below on dissemination)

Low priority assigned to designs that can speed research

Expanding limited concepts of rigor (eg, preference for, confidence in, or insistence on certain designs such as RCTs) by:

Funding agencies offering calls for proposals

Grant application reviewers

Researchers

"Customers" of research (stakeholders who use the findings)

Ensuring a blend of research team skills and interests

Skill and interest in stakeholder involvement in generating questions, articulating ultimate use of study findings, study design, implementation, reporting, and dissemination

Awareness of and respect for political as well as scientific concerns of stakeholders such as policy makers

Skill and comfort in building relationships with clinicians and clinics-consultative, cooperative, problem solving

Experience and confidence with the broader "palette" of research designs, including rapid learning in real-world experiments

Increasing clinician familiarity with being active research partners

Negative experiences or preconceptions about feasibility or practical value of doing research in the practice

Few or no current relationships with researchers

Unfamiliarity of working with researchers to turn practice concerns and curiosity into researchable questions

Unfamiliarity with building research data gathering into routine clinic systems rather than being an effortful "add on"

Not connecting research with more familiar quality improvement, rapidcycle learning

Raising priority on collection and reporting on context and resources

Limited researcher and reviewer expectation that data on resource use of interventions or on context information relevant to transportability or reinvention in new settings be gathered systematically or reported

Space limitations and/or customary priorities in journals that reduce additional context and resource data reporting

More powerfully bringing publication and dissemination to practical decision making

Limited readiness to publish replications of key findings in original or new contexts or to publish negative results of replication

Reaching those stakeholders who want to make research-based decisions at the time and place decisions are made

Limited dissemination in publications or forms in which stakeholders are already engaged, knowing that different forms of publication/ dissemination reach different stakeholders

\section{Changes to Address Challenges}

Harness stakeholder interest in timeliness to drive a cultural shift to shorten what is considered "rapid" or "timely" compared with present custom

Implement a variety of technical changes to research processes already suggested in literature $\mathrm{e}^{19,21,26,27,54}$

Use rapid-cycle testing of hypotheses, allowing ineffective ideas to "fail fast" and successful innovations to spread quickly

Link social media with traditional communications vehicles

Among all parties, build awareness of and comfort with a broader "palette" of research designs, so that research design is driven by the questions, rather than research questions driven by designs

Use professional meetings/training events to more clearly articulate features, pros/cons of different designs-their appropriate or promising scope of application

Propose an enhanced "job description" for research teams-a checklist of skills, interests, and relationships required for specific studies

Beyond essential methodologic, data-gathering, and analytic skills, include "softer" skills and methods such as shown in left column

Build up those skills through examples, conferences, and training among both existing and new researchers

Provide examples and assistance through professional venues and practice facilitation or technical assistance that help clinicians and researchers adjust mindset, methods, and interactions to create practical research partnerships along the lines described in the literature ${ }^{15,16,25}$

Adjust research announcements and grant review guidelines to ask for greater reporting on context and resources required; accompany by explanation of why

For publication in limited space, consider other methods such as web supplements to access detailed context and resource use data if not in standard published article

Publish replications (successful or not) in places where stakehold ers will find them

Reward researchers via funding and career paths for key replications, not only for new positive results

Create a stakeholder map-which stakeholders need what information from the study, in what form, and where it is most likely to be read

Create stakeholder-specific versions of core journal publications to increase reach of the information

$\mathrm{IRB}=$ institutional review board; $\mathrm{RCT}=$ randomized controlled trial.

questions and further their careers. On the other hand, researchers often experience clinicians as not interested in research, resistant to research protocols, or not being ready to implement evidence-based findings. This is not a perceived relationship between researchers and practitioners or other stakeholders that will carry us into a successful future. The 5 R's proposed embody the terms of a new and more transparent win-win partnership between researchers and stakeholders with important questions that research can help answer.

\section{Teach to This New Standard}

This new standard (and its implicit partnership between stakeholders and researchers) is especially important for students and those early in their careers, whether clinicians, researchers, policy makers, or others wishing to develop or use research evidence. The 5 R's are offered 
as teaching tools as well as research tools-helping all stakeholders wear constructive "hats" with each other when addressing important questions. Over time, this approach may lead to an improved relationship between the research and health care enterprises-on behalf of the public they both serve.

To read or post commentaries in response to this article, see it online at http://www.annfammed.org/content/12/5/447.

Key words: research design; healthcare research; evaluation research; partnership research; rapid research

Submitted July 17, 2013; submitted, revised, May 13, 2014; accepted June 2, 2014.

Funding support: This project has been funded in whole or in part with federal funds from the National Cancer Institute, National Institutes of Health, under contract No. HHSN261200800001E. Dr Stange's time is supported in part by a Clinical Research Professorship from the American Cancer Society.

Disclaimer: The content of this article does not necessarily reflect the views or policies of the National Cancer Institute or the Department of Health and Human Services, nor does mention of trade names, commercial products, or organizations imply endorsement by the US government.

\section{References}

1. Smith JM, Topol E. A call to action: lowering the cost of health care. Am J Prev Med. 2013;44(1)(Suppl 1):S54-S57.

2. Patient-Centered Outcomes Research Institute (PCORI). Funding announcement: Improving healthcare systems. May 22, 2012. http:// www.pcori.org/assets/PFA-Improving-Healthcare-Systems-05222012. pdf. Accessed Jul 15, 2013.

3. Nutting PA, Crabtree BF, Miller WL, Stange KC, Stewart E, Jaén C. Transforming physician practices to patient-centered medical homes: lessons from the national demonstration project. Health Aff (Millwood). 2011;30(3):439-445.

4. Fisher ES, Shortell SM. Accountable care organizations: accountable for what, to whom, and how. JAMA. 2010;304(15):1715-1716.

5. Selby JV, Beal AC, Frank L. The Patient-Centered Outcomes Research Institute (PCORI) national priorities for research and initial research agenda. JAMA. 2012;307(15):1583-1584.

6. Stange KC. Refocusing knowledge generation, application, and education: raising our gaze to promote health across boundaries. Am J Prev Med. 2011;41(4)(Suppl 3):S164-S169.

7. Balas EBS. Managing Clinical Knowledge for Health Care Improvement. Yearbook of Medical Informatics. Stuttgart, Germany: Schattauer; 2000.

8. Brownson RC, Colditz GA, Proctor EK, eds. Dissemination and Implementation Research in Health: Translating Science to Practice. 1st ed. New York, NY: Oxford University Press, Inc; 2012.

9. Kessler R, Glasgow RE. A proposal to speed translation of healthcare research into practice: dramatic change is needed. Am J Prev Med. 2011;40(6):637-644.

10. Moher D, Hopewell S, Schulz KF, et al; Consolidated Standards of Reporting Trials Group. CONSORT 2010 Explanation and Elaboration: Updated guidelines for reporting parallel group randomised trials. J Clin Epidemiol. 2010;63(8):e1-e37.

11. Schulz KF, Altman DG, Moher D, CONSORT Group. CONSORT 2010 statement: updated guidelines for reporting parallel group randomised trials. BMC Med. 2010;340:c332.
12. Higgins J, Green S. Cochrane Handbook for Systematic Reviews of Interventions. Updated 2011. http://www.cochrane-handbook.org. Accessed Jul 16, 2013.

13. Equator Network. Library for Health Research Reporting. EQUATOR Network Resource Center website. Updated 2013. http://www. equator-network.org/resource-centre/library-of-health-researchreporting. Accessed Jul 16, 2013.

14. Gold M, Siegel J, Russell L, Weinstein M. Cost Effectiveness in Health and Medicine. New York, NY: Oxford University Press; 2003.

15. Solberg LI, Glasgow RE, Unützer J, et al. Partnership research: a practical trial design for evaluation of a natural experiment to improve depression care. Med Care. 2010;48(7):576-582.

16. Kottke TE, Solberg LI, Nelson AF, et al. Optimizing practice through research: a new perspective to solve an old problem. Ann Fam Med. 2008;6(5):459-462.

17. Berwick DM. Broadening the view of evidence-based medicine. Qual Saf Health Care. 2005;14(5):315-316.

18. Rothwell PM. External validity of randomised controlled trials: "to whom do the results of this trial apply?" Lancet. 2005;365(9453): 82-93.

19. Glasgow RE, Chambers D. Developing robust, sustainable, implementation systems using rigorous, rapid and relevant science. Clin Trans/ Sci. 2012;5(1):48-55.

20. Kessler RS. The patient centered medical home: a great opportunity to move beyond brilliant and irrelevant. Transl Behav Med. 2012;2(3):311-312.

21. Riley WT, Glasgow RE, Etheredge L, Abernethy AP. Rapid, responsive, relevant (R3) research: a call for a rapid learning health research enterprise. Clin Transl Med. 2013;2(1):10.

22. Green LW. Making research relevant: if it is an evidence-based practice, where's the practice-based evidence? Fam Pract. 2008; 25(Suppl 1):i20-i24.

23. Krist AH, Glenn BA, Glasgow RE, et al. Designing a valid randomized pragmatic primary care implementation trial: the My Own Health Report (MOHR) project. Implement Sci. 2013;8:73.

24. Tunis SR, Stryer DB, Clancy CM. Practical clinical trials: increasing the value of clinical research for decision making in clinical and health policy. JAMA. 2003;290(12):1624-1632.

25. Solberg LI, Crain AL, Jaeckels N, et al. The DIAMOND initiative: implementing collaborative care for depression in 75 primary care clinics. Implement Sci. 2013;8(1):135.

26. Abernethy AP, Etheredge LM, Ganz PA, et al. Rapid-learning system for cancer care. J Clin Oncol. 2010;28(27):4268-4274.

27. Etheredge LM. A rapid-learning health system. Health Aff (Millwood). 2007;26(2):w107-w118.

28. Mays GP, Hogg RA. Expanding delivery system research in public health settings: lessons from practice-based research networks. J Public Health Manag Pract. 2012;18(6):485-498.

29. Ryan B. Data management and analysis methods. In: Denzin N, Lincoln Y, eds. Handbook of Qualitative Research. 2nd ed. Thousand Oaks, CA: Sage Publications; 2000:769-802.

30. Green LW, Glasgow RE. Evaluating the relevance, generalization, and applicability of research: issues in external validation and translation methodology. Eval Health Prof. 2006;29(1):126-153.

31. Glasgow RE, Klesges LM, Dzewaltowski DA, Bull SS, Estabrooks P. The future of health behavior change research: what is needed to improve translation of research into health promotion practice? Ann Behav Med. 2004;27(1):3-12.

32. Ritzwoller DP, Sukhanova A, Gaglio B, Glasgow RE. Costing behavioral interventions: a practical guide to enhance translation. Ann Behav Med. 2009;37(2):218-227.

33. Ritzwoller DP, Sukhanova AS, Glasgow RE, et al. Intervention costs and cost-effectiveness for a multiple-risk-factor diabetes selfmanagement trial for Latinas: economic analysis of Viva bien! Transl Behav Med. 2011;1(3):427-435. 
34. Porter ME. What is value in health care? N Engl J Med. 2010;363(26): 2477-2481.

35. deBronkart D. How the e-patient community helped save my life: an essay by Dave deBronkart. BMJ. 2013;346:f1990.

36. Cohn S, Clinch M, Bunn C, Stronge P. Entangled complexity: why complex interventions are just not complicated enough. J Health Serv Res Policy. 2013;18(1):40-43.

37. Ioannidis JP. Effect of the statistical significance of results on the time to completion and publication of randomized efficacy trials. JAMA. 1998;279(4):281-286.

38. Tomoaia-Cotisel A, Scammon DL, Waitzman NJ, et al. Context matters: the experience of 14 research teams in systematically reporting contextual factors important for practice change. Ann Fam Med. 2013;11(Suppl 1):S115-S123.

39. Crain AL, Solberg LI, Unützer J, et al. Designing and implementing research on a statewide quality improvement initiative: the DIAMOND study and initiative. Med Care. 2013;51(9):e58-e66.

40. Glasgow RE, Magid DJ, Beck A, Ritzwoller D, Estabrooks PA. Practical clinical trials for translating research to practice: design and measurement recommendations. Med Care. 2005;43(6):551-557.

41. Cohen D, McDaniel RR Jr, Crabtree BF, et al. A practice change model for quality improvement in primary care practice. J Healthc Manag. 2004;49(3):155-168, discussion 169-170.

42. Allen J, Linnan L, Emmons K. Fidelity and its relationship to implementation effectiveness, adaptation and dissemination. In: Brownson R, Colditz G, Proctor E, eds. Dissemination and Implementation Research in Health: Translating Science to Practice. 1st ed. New York, NY: Oxford University Press; 2012:281-303.

43. Cohen DJ, Tallia AF, Crabtree BF, Young DM. Implementing health behavior change in primary care: lessons from prescription for health. Ann Fam Med. 2005;3(Suppl 2):S12-S19.

44. Cohen DJ, Crabtree BF, Etz RS, et al. Fidelity versus flexibility: translating evidence-based research into practice. Am J Prev Med. 2008;35(5)(Suppl):S381-S389.
45. Cohen D, Leviton L, Isaacson N, Tallia A, Crabtree B. Online diaries for qualitative evaluation: gaining real-time insights. Am J Eval. 2006;27(2):1-22.

46. Etz RS, Cohen DJ, Woolf SH, et al. Bridging primary care practices and communities to promote healthy behaviors. Am J Prev Med. 2008;35(5)(Suppl):S390-S397.

47. Balasubramanian BA, Cohen DJ, Clark EC, et al. Practice-level approaches for behavioral counseling and patient health behaviors. Am J Prev Med. 2008;35(5)(Suppl):S407-S413.

48. Cohen DJ, Balasubramanian BA, Isaacson NF, Clark EC, Etz RS, Crabtree BF. Coordination of health behavior counseling in primary care. Ann Fam Med. 2011;9(5):406-415.

49. Glasgow R, Kessler R, Ory M, et al. Conducting rapid, relevant research: lessons learned from the My Own Health Report (MOHR) project. Am J Prev Med. 2014;47(2):212-219.

50. Thorpe KE, Zwarenstein $M, O x m a n A D$, et al. A pragmatic-explanatory continuum indicator summary (PRECIS): a tool to help trial designers. J Clin Epidemiol. 2009;62(5):464-475.

51. Senge PM. Fifth Discipline: Mastering the Five Practices of the Learning Organization. New York, NY: Doubleday \& Co; 1990.

52. Gaglio B, Shoup JA, Glasgow RE. The RE-AIM framework: a systematic review of use over time. Am J Public Health. 2013;103(6):e38-e46.

53. Kessler RS, Purcell EP, Glasgow RE, Klesges LM, Benkeser RM, Peek CJ. What does it mean to "employ" the RE-AIM model? Eval Health Prof. 2013;36(1):44-66.

54. Wagner EH. Academia, chronic care, and the future of primary care. J Gen Intern Med. 2010;25(Suppl 4):S636-S638.

55. Committee on Quality of Health Care in America. Crossing the Quality Chasm: A New Health System for the 21st Century. Washington, DC: National Academy Press; 2001.

56. Gluck ME, Radomski L. The AcademyHealth Listening Project Report: Improving the Evidence Base for Medicare Policymaking. AcademyHealth. Updated February 2014. http://academyhealth.org/files/publications/listeningprojectmedicare.pdf. Accessed Apr 4, 2014. 